
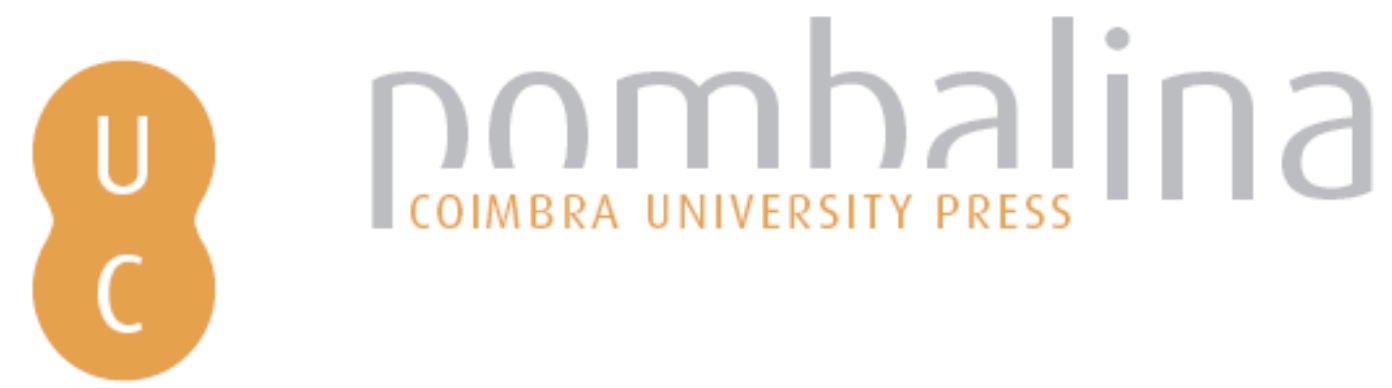

\title{
Começar de novo: a «repetição do nascimento» e a transformação política do Egito na viragem para o I Milénio
}
Autor(es):
Sousa, Rogério
Publicado por: Imprensa da Universidade de Coimbra
URL
persistente:
URI:http://hdl.handle.net/10316.2/45212
DOI:
DOI:https://doi.org/10.14195/978-989-26-1626-1_3
Accessed : $\quad$ 26-Apr-2023 15:12:05

A navegação consulta e descarregamento dos títulos inseridos nas Bibliotecas Digitais UC Digitalis, UC Pombalina e UC Impactum, pressupõem a aceitação plena e sem reservas dos Termos e Condições de Uso destas Bibliotecas Digitais, disponíveis em https://digitalis.uc.pt/pt-pt/termos.

Conforme exposto nos referidos Termos e Condições de Uso, o descarregamento de títulos de acesso restrito requer uma licença válida de autorização devendo o utilizador aceder ao(s) documento(s) a partir de um endereço de IP da instituição detentora da supramencionada licença.

Ao utilizador é apenas permitido o descarregamento para uso pessoal, pelo que o emprego do(s) título(s) descarregado(s) para outro fim, designadamente comercial, carece de autorização do respetivo autor ou editor da obra.

Na medida em que todas as obras da UC Digitalis se encontram protegidas pelo Código do Direito de Autor e Direitos Conexos e demais legislação aplicável, toda a cópia, parcial ou total, deste documento, nos casos em que é legalmente admitida, deverá conter ou fazer-se acompanhar por este aviso.

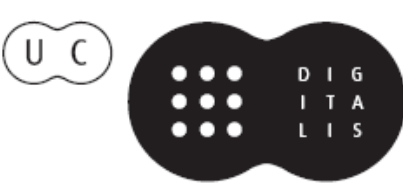




\section{Arqueologias de Império}

\section{Delfim Leão, José Augusto Ramos, Nuno Simões Rodrigues (coords.)}

IMPRENSA DA UNIVERSIDADE DE COIMBRA 


\title{
COMEÇAR DE NOVO: \\ A «REPETIÇÃo do NASCIMENTO» E A TRANSFORMAÇÃo POLÍTICA DO EgITO NA VIRAGEM PARA O I MILÉNIO' \\ (Starting anew: the "repetition of birth» and Egypt's political transformation on the brink of the 1st Millenium)
}

RogérIO SOUSA

(solar.benu@gmail.com; ORCID: 0000-0002-8253-1707)

Universidade de Lisboa, Faculdade de Letras, Centro de História Centro de Estudos Clássicos e Humanísticos, Universidade de Coimbra

\begin{abstract}
Resumo - A desintegração política que ocorreu no Egito no final do Império Novo partilha muitos aspetos em comum com a crise que afetou as civilizações da bacia do Mediterrâneo na transição da Idade do Bronze para a Idade do Ferro. Muito mais bem documentada no Egito do que noutros contextos, esta transição não irrompeu de forma violenta ou acompanhada por uma crise cultural profunda. Ainda assim, o Terceiro Período Intermediário apresenta uma organização política completamente distinta que parece ter sido posta em prática ao longo da «Repetição do Nascimento» através da ação combinada de Herihor - e dos seus sucessores no reino do Sul - e de Ramsés XI no reino do Norte.

Palavras-CHave: Repetição do Nascimento; Herihor; Ramsés XI.
\end{abstract}

Abstract - The political disintegration occurred in Egypt at the end of the New Kingdom has much in common with the crisis that affected the civilizations of the Mediterranean basin in the transition from the Bronze Age to the Iron Age. Much better documented in Egypt than elsewhere, this transition did not irrupt violently with a sense of cultural crisis. Nevertheless, the Third Intermediate Period presents a completely distinct political organization of Egypt that seems to have been put in place during the «Repetition of births» through a combined action of Herihor and his successors in the South and Ramses XI in the North.

KeYwORDs: Repetition of birth; Herihor; Ramses XI.

O fim da XX dinastia (c. 1100 a.C) e do Império Novo foi grandemente determinado pelas ondas de choque provocadas pelas grandes migrações causadas pela queda do mundo micénico e do império hitita. Embora o Egito tenha sido atingido apenas marginalmente por estes fenómenos, a verdade é que a batalha de Ramsés III contra os Povos do Mar representa um choque de civilizações que, apesar da vitória obtida, não se traduziu, de forma alguma no afastamento do inimigo ${ }^{2}$. Às

\footnotetext{
${ }^{1}$ Este trabalho foi apoiado por Fundos Nacionais através da FCT - Fundação para a Ciência e a Tecnologia no âmbito do projeto UID/HIS/04311/2013 e do projecto UID/ELT/00196/2013.

${ }^{2}$ Os líbios constituem uma presença influente no Egito. Embora as incursões dos Mechuech e dos Libu tivessem sido repelidas por Merenptah e Ramsés III muitos imigrantes
} 
populações líbias autóctones juntaram-se mercenários oriundos dos chamados «Povos do Mar» que se instalaram cada vez com mais expressão no Delta ${ }^{3}$, desenvolvendo uma aristocracia militar que havia de marcar indelevelmente a geografia política e militar do Egito ${ }^{4}$. Adicionalmente, muitos imigrantes continuaram a instalar-se no Delta, com um cunho fortemente militarizado. No final do Império Novo o exército era já quase inteiramente constituído por mercenários líbios 5 .

O domínio dos Mechuech no Egito é assim equivalente à irrupção dos Etruscos na Itália, ou dos Dórios na Grécia, ou dos Filisteus na Palestina. Em todos estes casos, os processos de penetração das novas populações foram acompanhados pela incapacidade crescente do poder central em garantir a conectividade política, desencadeando uma regionalização crescente, com as populações locais entregues a si mesmas ${ }^{6}$.

O final do Império Novo é, portanto, antes de mais a expressão de um fenómeno global que afetou todo o Próximo Oriente e Mediterrâneo, desde a Índia ao Egeu. Internamente, este fenómeno traduziu-se na desintegração do aparelho burocrático real, a qual se acelerou na proporção directa do empobrecimento das populações. Sabe-se que uma série de más colheitas ocorreram durante o reinado de Ramsés VII e prosseguiram com os seus sucessores, levando a um aumento do preço do trigo e a períodos de fome ${ }^{7}$. O empobrecimento foi geral e a ineficácia da administração central agravou-o ainda mais, gerando-se, como refere Jan Assman, uma crise de penetração e de distribuição. Toda a infraestrutura crucial para o funcionamento de uma economia redistributiva estava à beira do colapso: os bens não chegavam aos armazéns reais, e o abastecimento proporcionado por estes armazéns era insuficiente, daí resultando fome, instabilidade social e empobrecimento geral.

Os reinados de Ramsés IX, Ramsés X e Ramsés XI representam o momento mais grave desta tendência. Como os seus antecessores da XIX e da XX dinastia, o faraó governava a partir da sua capital, Pi-Ramsés, situada no Delta oriental, longe, portanto, dos principais centros locais do Egito e aparentemente sem capacidade real de intervenção neste processo.

Sintomaticamente nem as obras reais de grande importância simbólica e política, como a construção dos túmulos reais, foram poupadas. No reinado de

continuaram a instalar-se no Delta, com um cunho fortemente militarizado (Wainwright 1962, 89-99). No final do Império Novo o exército era já quase inteiramente constituído por mercenários líbios (Taylor 2000, 335).

${ }^{3}$ Assmann 2002, 281.

${ }^{4}$ Este fenómeno é visível através da onomástica: as famílias mais influentes, tanto no norte como no sul, apresentam indivíduos com nomes aparentemente de origem líbia. A presença líbia poderá ser mais expressiva, sobretudo se admitirmos que sob nomes egípcios se ocultem também indivíduos de origem líbia (Taylor 2000, 335).

${ }^{5}$ Taylor 2000, 335.

${ }^{6}$ Assmann 2002, 281.

${ }^{7}$ Trigger et al. 1983, 228. 
Ramsés IX, o fornecimento deficiente de géneros aos trabalhadores dos túmulos reais iria mesmo motivar uma greve consubstanciada num vigoroso movimento reivindicativo em Deir el-Medina, que levou os operários a dirigirem-se ao sumo sacerdote de Ámon, apresentando-lhe as suas queixas ${ }^{8}$. Segundo a documentação, eles acabaram por ser pagos com o trigo retirado do celeiro dos templos de Montu, quando tal pagamento competia às autoridades «civis» sob as ordens diretas do vizir de então, Khamon. Nos reinados de Ramsés X (KV 18) e de Ramsés XI (KV 4) a situação foi aparentemente ainda pior, já que nenhum dos túmulos foi terminado.

Durante este período, a região de Tebas foi assolada por grupos armados provenientes do deserto ocidental, originando um período crítico de violência e fome que mais tarde seria evocado como o «ano das hienas». Estes grupos tinham provavelmente origem líbia, mas é provável que vivessem no Egito há várias gerações e que, em algum momento, tivessem estado ao serviço do próprio faraó. Sabe-se que Ramsés III, na continuação de idênticas atitudes tomadas pelos seus antecessores, tinha instalado várias colónias de líbios e de sírios no país, alguns deles servindo como mercenários no exército".

A situação de crise geral, no entanto, tinha tornado perigosos estes grupos, que aproveitando a debilidade crescente do sistema, pilhavam as populações mais vulneráveis. As incursões depredatórias no território tebano motivaram mesmo o abandono de Deir el-Medina, cujos aldeões se refugiaram no complexo funerário de Ramsés III de Medinet Habu, entretanto transformada em cidadela fortificada.

A anarquia crescente foi agravada pela corrupção dos funcionários, gerando um processo que se reforçava mutuamente. Quanto maior era a ineficácia do aparelho burocrático real maior era a corrupção, o que gerava ainda mais ineficácia. Este processo é exemplarmente demonstrado pelo saque organizado aos túmulos da necrópole. Este processo é documentado no Papiro Abbott, o qual conserva uma série de relatórios relativos a roubos que tiveram lugar no ano 16 de Ramsés IX. O escândalo estalou aparentemente devido à rivalidade entre o governador de Tebas, Paser, e o governador da necrópole, Pauer-ré. Em face das denúncias, o vizir, Khaemuaset, ordenou uma comissão para investigar as alegações ${ }^{10}$. Dos dez túmulos investigados, apenas o de Amen-hotep I se apresentava então intacto. Todos os restantes haviam sido espoliados em todo ou em parte ${ }^{11}$.

\footnotetext{
${ }^{8}$ Em Araújo 1999, 153, nota 26.

${ }^{9}$ Araújo 1999, 115.

${ }^{10}$ A respeito dos roubos efetuados na necrópole ver Goelet 1996, 107-27.

${ }^{11}$ Clayton 1994, 171. Foi em Deir el-Medina que foi encontrada a documentação referente aos roubos aos túmulos reais. Os culpados foram julgados no templo de Maet situado junto ao templo de Montu em Karnak. O vizir Khaemuaset, o governador de Tebas Paser, o sumo sacerdote de Ámon Amen-hotep e o governador da necrópole Pauer participaram no julgamento dos culpados, que foram severamente punidos.
} 
Apesar da investigação judicial em curso, o saque continuou ao longo dos anos seguintes, prolongando-se até ao reinado de Ramsés XI, durante o qual se registaram roubos no Vale das Rainhas, em Medinet Habu e no Ramesseum ${ }^{12}$. Em tempos de escassez, as riquezas ocultas na necrópole constituíam, portanto, um foco crítico de instabilidade para a região tebana.

Perante o recuo da administração central, foi nos templos que se manteve em funcionamento uma administração local que, aliviada da supervisão faraónica, oferecia o terreno ideal para a actividade de funcionários corruptos. São conhecidos excessos cometidos por sacerdotes em Elefantina, relatados no Papiro de Turim $1887^{3}$. Esta tendência atingiu certamente proporções bem mais significativas em torno dos grandes templos do Egito, onde a riqueza era ainda muito significativa. O templo de Ámon detinha dois terços da terra arável do Egito, noventa por cento da frota fluvial, oitenta por cento das oficinas. O seu controlo da economia do país era absoluto e tornou-se inevitável que o sumo sacerdote de Ámon adquirisse um peso político sem precedentes.

Numa cerimónia ocorrida no ano 10 de Ramsés IX, no templo de Ámon em Karnak, o sumo pontífice Amen-hotep foi cumulado de favores, alguns dos quais consistiam na transferência dos tributos destinados ao próprio faraó para o tesouro do templo de Ámon. Esta cerimónia foi gravada no muro situado entre o sétimo e o oitavo pilone em Karnak. Nela pode ver-se Amen-hotep diante do faraó Ramsés IX e, facto inusitado, ambos são representados com o mesmo tamanho, algo que noutros tempos teria sido inaceitável e anómalo tendo em conta todas as convenções milenares da ideologia real egípcia ${ }^{14}$.

Esta demonstração de poder foi apenas o prelúdio de um longo pontificado. Amen-hotep sucedera ao seu irmão mais velho, Nesiamon ${ }^{15}$. Sintomaticamente à medida que o aparelho burocrático real se degradava, a cultura de mérito que antes ditava o acesso aos cargos de topo da hierarquia, era agora substituída pelo carácter hereditário dos mesmos. Guindado no cargo pela legitimidade conferida pela sua linhagem familiar, Amen-hotep manteve-o durante o reinado de Ramsés $\mathrm{X}$, acumulando-o com o cargo de intendente dos trabalhos no domínio de Ámon, grande intendente do palácio real e, tal como o seu pai, chefe dos sacerdotes de todos os deuses.

${ }^{12}$ Ver Dodson 2012, 10.

${ }^{13}$ Araújo 1999, 118.

${ }^{14}$ Uma outra representação ilustra Amen-hotep oferecendo um elemento floral do culto de Montu ao faraó, o qual aparece na imagem com o mesmo tamanho que o sumo sacerdote de Ámon. Araújo 1999 154, nota 34. Ver também Černý 1965, 629.

${ }_{15}$ Araújo 1999, 113. Ver também Bierbrier 1975, 3-13. A família de Amen-hotep estava unida com outra família importante que descendia de Bakenkhonsu (sumo sacerdote de Ámon no tempo de Ramsés III). 


\section{O golpe militar de Panehesi}

Esta tendência foi brutalmente interrompida pelo golpe militar liderado por Panehesi, o Vice-rei de Kuch. Uma carta endereçada pelo faraó Ramsés XI a Pahenesi datada do Ano 17 atesta as boas relações entre ambos e seguramente antecede o eclodir daquele evento ${ }^{16}$. Provavelmente incentivado pelo próprio faraó ${ }^{17}$, Panehesi, o homem forte do momento, ataca posições rebeldes ao norte de Tebas, dominando Hardai, a capital da XVII sepat do Alto Egito. Na sequência desta intervenção, Panehesi fez o impensável e depôs o sumo sacerdote Amenhotep «sem que nele houvesse falta» ${ }^{18}$. Embora eventualmente sancionado pelo próprio faraó, o golpe desencadeou uma oposição e indignação tal que Amenhotep foi reconduzido novamente nas suas funções.

Apesar de documentado em várias fontes, incluindo o próprio texto autobiográfico de Amen-hotep, este acontecimento marcante para a evolução política registada ao longo da XXI dinastia e todo o Terceiro Período Intermediário possui uma datação muito incerta, mas é provável que tenha ocorrido antes do Ano 19 de Ramsés XI, portanto antes da «Repetição do Nascimento ${ }^{19}$.

O certo é que ambos os protagonistas deste episódio viram a sua importância política esfumar-se daí em diante. Na sequência deste incidente, o poderoso Panehesi é repelido para lá das fronteiras meridionais da Núbia e perde desde então toda a sua influência em Tebas ${ }^{20}$, passando doravante a ser qualificado com o pejorativo determinativo de «inimigo» ${ }^{21}$. Amen-hotep, por outro lado, viu daí em diante secundarizado o seu estatuto. Desconhece-se o destino final de Amen-hotep, mas as escavações arqueológicas no seu túmulo, que se erguia imponente em Dra Abu el-Naga, não revelaram qualquer vestígio de ter sido usado ${ }^{22}$.

\section{A «REPETiÇão Do NASCimento»}

No Ano 19 de Ramsés XI, os documentos tebanos passam a ser datados de acordo com uma nova era, a Uhem-mesut, a «Repetição do Nascimento»"23. É o caso do Papiro Mayer A que faz referência ao "Ano 1 da Repetição do Nascimento» ou do Papiro Abbott que alude ao «Ano 1, primeiro mês de Akhet, dia 2,

${ }^{16}$ Dodson 2012, 15.

${ }^{17}$ Araújo 1999, 115. Também em Kitchen 1986, 247.

${ }_{18}^{18}$ PBM EA10383: 2 2.5. Em Dodson 2012, 15.

${ }^{19}$ Dodson 2012, 14.

${ }^{20}$ Černý 1965, 633. Ver Taylor 2000, 331.

${ }^{21}$ Dodson 2012, 16.

${ }^{22}$ Cooney 2011, 10.

${ }^{23}$ A expressão whm-mswt (uhem-mesut), «Repetição do Nascimento», derivava, segundo Gardiner, de uma fórmula metafórica alusiva ao renascimento cíclico da lua. Em Gardiner 1961, 127. Também em Araújo 1999, 124. 
correspondendo ao Ano 19 (de Ramsés XI)»²4.

Era a terceira vez na história egípcia que ocorria uma «Repetição do Nascimento». A primeira ocorreu com Amenemhat I (1991 a.C) e a segunda com Seti I (1295 a.C). A expressão havia sido usada para proclamar esses reinados como o início de uma nova era. No Egito o interesse em assegurar a continuidade era em geral mais forte do que o desejo de mudança. Iniciar um período de governação proclamando-o como um renascimento correspondia a um desejo firme de afirmar uma rutura com o passado recente. Amenemhat I havia usado esta expressão para se distanciar do Primeiro Período Intermediário e Seti I para se distanciar do período amarniano e de algum modo buscavam o regresso a uma certa «ortodoxia». No entanto, ao contrário das anteriores, a nova proclamação de um renascimento não evocava o regresso a um sistema de governação previamente existente. Pelo contrário, anunciava uma nova era que verdadeiramente se distinguia de tudo quanto havia existido previamente ${ }^{25}$. Esta era de renascimento não corresponde a um período de florescimento cultural, mas representa uma das mais importantes viragens da história egípcia.

\section{HERIHOR E A FORMULAÇÃo dA TEOCRACIA de ÁMON}

A historiografia deste período é bastante problemática. A reconstrução atualmente mais consensual faz coincidir o Ano 1 da «Repetição do Nascimento» com o início do pontificado de Herihor, pelo que se deduz que a nova contagem do tempo é implementada após o afastamento se não definitivo pelo menos efetivo de Amen-hotep daquele cargo.

A nomeação de Herihor como sumo sacerdote de Ámon afigura-se portanto em clara rutura com o estatuto anteriormente detido por Amen-hotep, o qual devia a legitimidade do seu cargo à sua linhagem familiar. A nomeação de Herihor como sumo sacerdote de Ámon contradiz esta tendência, já que não só não apresenta qualquer genealogia, como não seguira sequer uma carreira sacerdotal prévia: os seus títulos mencionam unicamente o cargo de superintendente dos carros de guerra e o de hauti (comandante do exército do Egito) ${ }^{26}$. É portanto na qualidade de chefe militar que Herihor assume o pontificado tebano.

A nomeação de Herihor como sumo sacerdote de Ámon, coroava portanto uma carreira militar, mais do que sacerdotal ${ }^{27}$. Deste modo, é legítimo questionar até que ponto Herihor representaria efetivamente os interesses do templo de Ámon ${ }^{28}$. A nomeação de Herihor representou portanto uma rutura profunda

\footnotetext{
${ }^{24}$ Araújo 1999, 116. Para outras fontes para a «Repetição do Nascimento» ver também Černý 1927, 194-98.

${ }^{25}$ Assmann 2002, 289.

${ }^{26}$ Araújo 1999, 121.

${ }^{27}$ Clayton 1994, 171.

${ }^{28}$ Tradicionalmente, Herihor é visto como o arauto do clero de Ámon. Veja-se Araújo 1999,
} 
nesta ordem e originou seguramente uma reação no seio do clero tebano. A nova contagem do tempo que decorria da «Repetição do Nascimento» de certa forma sancionava e legitimava o carácter excecional da eleição de Herihor e muito provavelmente foi implementada para consolidar a rutura com o passado recente.

A partir de Herihor, os sumo sacerdotes de Ámon seriam doravante generais, chefes militares cuja origem egípcia é, na maior parte dos casos, altamente questionável. Contrariando os privilégios das linhagens locais e alicerçando o seu poder na força militar, a nova linhagem de sumo pontífices introduzia uma rutura profunda na organização do clero amoniano, rutura essa que parece ter servido os interesses do faraó ${ }^{29}$.

A formulação de uma nova era e de um monarca em Tebas fazia inaugurar uma nova relação política com Ramsés XI. Estas relações que antes eram domésticas assumiam agora $\mathrm{o}$ carácter de relações entre $\operatorname{estados}^{30}$. E no entanto, não resultou desta cisão o aumento de hostilidade entre Tebas e o Norte. Muito pelo contrário. Uma espécie de concordata caracterizou as suas relações políticas. A «Repetição do Nascimento» utilizava os instrumentos da diplomacia internacional tão eficazmente elaborados ao longo do período ramséssida, para assegurar o domínio da tensão interna, a qual continuou a originar incidentes ao longo de toda a XXI dinastia ${ }^{31}$.

A nomeação de Herihor teve, portanto um significado político indissociável da declaração da «Repetição do Nascimento», como uma nova era. Herihor empenhou-se desde logo na estabilização da necrópole tebana, essencial para controlar a região. Não é certamente por acaso que a maior parte da documentação referente à «Repetição do Nascimento» se relacione com julgamentos relacionados com os roubos efetuados na necrópol ${ }^{32} \mathrm{e}$ com as retumulações reais, as quais, aparentemente se iniciaram sob o seu comando. Registos do seu reinado são frequentes entre os restauros feitos às múmias e aos ataúdes reais descobertos no túmulo TT $320^{33}$.

116. Também Černý 1965, 634.

${ }^{29}$ Sinais da resistência a estas medidas iriam continuar a fazer-se sentir no clero tebano pelo menos até o pontificado de Menkheperré, altura em que os últimos focos de resistência parecem ter sido definitivamente eliminados.

${ }^{30}$ Assmann 2002, 289.

${ }^{31}$ A morte, aparentemente prematura, de Masaharta parece ter sido acompanhada por distúrbios na região tebana, os quais terão culminado nos acontecimentos narrados na Estela do Banimento, que assinala o regresso de Menkheperré a Tebas com o intuito explícito de repor a ordem: «foi ao sul, em valor e vitória, para pacificar a terra e suprimir o seu inimigo» (Araújo 1999, 141). Em seguida, na sequência de uma decisão oracular, Menkheperré anuncia o regresso de exilados (Goff 1979, 66).

${ }^{32}$ A este respeito ver Peet 1930.

${ }^{33}$ As inscrições feitas nas faixas mortuárias das múmias reais, sobretudo nas de Ramsés II e de Seti I, são fontes de informação decisivas para a cronologia da «Repetição do Nascimento». $\mathrm{O}$ restauro destas múmias teria sido ordenado por Herihor, provavelmente na sequência da profanação dos seus túmulos. 
Até ao Ano 5 da «Repetição do Nascimento» nem Herihor em Tebas, nem Smendes em Tânis, detêm ainda qualquer prerrogativa real, como se depreende do relato patente na Viagem de Uenamon. Datam ainda desta fase, as campanhas de decoração do templo de Khonsu, o deus lunar filho de Ámon, erguido no recinto do templo de Ámon-Ré em Karnak. Na sala hipóstila do templo de Khonsu, Herihor enverga trajes sacerdotais mas é representado à mesma escala do faraó Ramsés XI, executando os mesmos gestos litúrgicos, em princípio reservados unicamente ao faraó. Note-se que, nem mesmo o sumo sacerdote Amen-hotep havia sido apresentado desta forma ${ }^{34}$.

Contudo, no Ano 6 da «Repetição do Nascimento» (Ano 24 de Ramsés XI), verifica-se a assunção da realeza por parte de Herihor e a consequente eleição de Piankh como sumo sacerdote de Ámon no Ano 7. Com a sua aclamação real, uma nova contagem do tempo é adicionada, desta feita baseada nos anos de reinado de Herihor. Esta viragem é documentada na decoração do pátio colunado do templo de Khonsu, em Karnak, onde Herihor figura já ataviado como um faraó e dotado de uma titularia real ${ }^{35}$. E no entanto, o seu nome de coroação - nome de rei do Alto e do Baixo Egito - não era outro senão o do seu cargo, o de sumo sacerdote de Ámon. A adoção deste título como nome de rei do Alto e do Baixo Egito, o mais importante e significativo da titulatura real e aquele que melhor condensava a quintessência do programa de reinado do faraó, indica que Herihor integrava o cargo de sumo sacerdote de Ámon na sua definição como «faraó», o que parece refletir o desejo de reunir num único indivíduo a autoridade civil, militar e religiosa. Mas não é tudo. Ao adotar as prerrogativas reais, Herihor iniciou, como era habitual, uma nova contagem do tempo através dos seus próprios anos de reinado ${ }^{36}$.

A introdução de uma nova contagem do tempo (que se adiciona à contagem da «Repetição do Nascimento» e do reinado de Ramsés XI) está entre as mais significativas medidas adotadas por Herihor, assinalando a autonomia política do território de Tebas em relação à governação de Ramsés XI. A adoção da titulatura real de Herihor surge portanto como uma consequência decorrente da formulação de um novo ciclo político. O título de sumo sacerdote inscrito na cartela real tem um papel chave na definição deste novo «estado» tebano: seria na qualidade de pontífice que Herihor iria adotar as prerrogativas reais, submetendo a sua estratégia política aos ditames superiores do culto de Ámon. Em suma, a proclamação do estatuto real de Herihor traduz a implementação em pleno de um novo sistema político em Tebas, a teocracia de Ámon.

\footnotetext{
${ }^{34}$ Dodson 2012, 22.

${ }^{35}$ Clayton 1994, 171.

${ }^{36}$ James et Morkot 2010, 255.
} 
Ao associar o cargo de sumo pontífice com o exercício do poder real, este novo sistema político tinha uma lógica concentracionária. Tradicionalmente o sistema egípcio assentava na separação estrita entre a monarquia e o exercício de responsabilidades administrativas. Era um facto sem precedentes que um rei fosse sumo sacerdote e chefe militar ${ }^{37}$. O novo sistema político, a teocracia de Ámon, assentava portanto na concentração de todos os poderes num único indivíduo que era, acima de tudo, um chefe militar.

\section{Piankh e o fim da «Repetição do Nascimento»}

Ao que tudo indica Herihor teve uma extensa prole. No pátio colunado do templo de Khonsu, em Karnak, um extenso cortejo liderado por Nedjemet, a sua mulher, apresenta 19 filhos e 19 filhas ${ }^{38}$. Apesar disso, no Ano 7 da «Repetição do Nascimento» (Ano 24 de Ramsés XI), um ano após a assunção da realeza por Herihor, seria Piankh a ser eleito sumo sacerdote de Ámon.

É sintomático que a sucessão do sumo pontífice não se tenha traduzido na implementação de uma nova contagem do tempo, como era a regra no sistema de sucessão faraónico, o que demonstra bem, a demarcação de poderes entre Herihor e Piankh ${ }^{39}$. Durante o seu pontificado Piankh autointitula-se o «general do faraó», expressão que se pode aplicar tanto a Herihor como a Ramsés $\mathrm{XI}^{40} \mathrm{e}$ que, de resto, se justificava em pleno, já que ao longo do seu curto pontificado, Piankh parece ter desempenhado sobretudo o papel de chefe militar, empenhando-se em campanhas militares dirigidas na Núbia, reclamando o cargo de vice-rei de Kuch. As suas campanhas militares mantiveram-no no encalço de Panehesi mas o controlo dos preciosos recursos de Kuch - as minas de ouro e as rotas caravaneiras com a África subsaariana - estava perdido ${ }^{41}$.

Adicionalmente, Piankh empenhou-se em assegurar a eliminação dos opositores ao regime. Numa carta dirigida a Nedjemet, Piankh não hesita em referir despreocupadamente o seu envolvimento no assassinato de dois polícias ${ }^{42}$, ciente da sua autonomia em relação ao poder real: «Quanto ao faraó (vida, saúde e prosperidade) como poderia ele aqui chegar? E a quem é o faraó ainda superior? $\aleph^{43}$.

${ }^{37} \mathrm{O}$ rei não se limitava a delegar estas funções num oficial eleito: nas cúpulas da hierarquia estas responsabilidades estavam bem delimitadas. Nem estes cargos eram atribuídos aos membros da família real. A exceção era o cargo de general supremo, cargo que só se tornou prevalente no período ramséssida e era exercido pelo príncipe herdeiro. Os vizires (um para o Sul e outro para o Norte) e o sumo sacerdote de Âmon eram recrutados de outras famílias. Em Assmann 2002, 290.

${ }^{38}$ Dodson 2012, 34-25.

${ }^{39}$ James et Morkot 2010, 255.

${ }^{40}$ Goff $1979,54$.

${ }^{41}$ Taylor 2000, 331.

${ }^{42}$ Dodson 2012, 32.

${ }^{43}$ PBerlim 10487 (LRL21). 
Em todo o caso, apesar da atitude insolente, as relações de Piankh com Ramsés XI mantiveram-se com aparente normalidade. Uma inscrição datada do Ano 7 da «Repetição do Nascimento», redigida no pavilhão de Amen-hotep II em Karnak faz referência ao «rei do Alto e do Baixo Egito Menmaetré-setepenamon», Ramsés XI, mencionando um oráculo solicitado por Piankh ${ }^{44}$.

Piankh e Ramsés XI parecem ter morrido sensivelmente na mesma altura $^{45}$. Piankh faleceu no Ano 10 da «Repetição do Nascimento» (Ano 28 de Ramsés XI, Ano 5 de Herihor) e Ramsés XI no Ano 11 da «Repetição do Nascimento». Refletindo os ventos de mudança impostos por Herihor na necrópole tebana, Ramsés XI não parece ter sido sepultado no túmulo que havia sido preparado para si no Vale dos Reis (KV 4). As pesquisas desenvolvidas em 1979-1980 por John Romer ao serviço do Museu de Brooklyn apontam para a possibilidade do túmulo ter permanecido inacabado e que o faraó não tenha sido de facto aí sepultado. A verdade é que a múmia de Ramsés XI não foi encontrada em nenhum dos esconderijos tebanos usados para inumar as múmias reais do Império Novo ${ }^{46}$.

Doravante Pinedjem I, filho de Piankh, iria assumir o pontificado tebano, e a contagem do tempo prosseguiu com o reinado de Herihor, o qual poderá ainda ter-se prolongado por mais 15 anos $^{47}$. Durante o pontificado de Pinedjem I é notório que o túmulo de Ramsés XI foi usado como oficina para reciclar material funerário proveniente dos túmulos KV 20 (Hatchepsut), KV 34 (Tutmés III) e presumivelmente KV 38 (Tutmés I) ${ }^{48}$, refletindo a mudança dramática da política oficial tebana relativamente ao culto dos antepassados reais.

No Norte, Smendes ascendeu ao trono, inaugurando a XXI dinastia. Também o sumo pontífice tebano Pinedejm I acabaria por assumir abertamente prerrogativas reais (no Ano 16 de Herihor) ${ }^{49}$ e serão, na prática, os seus descendentes que irão reger os destinos das Duas Terras, Psusennes I em Tânis e Menkheperré em Tebas.

${ }^{44}$ Goff 1979, 52. Inscrição e tradução em Nims 1948, 157-62.

${ }^{45}$ Clayton 1994, 176.

${ }^{46}$ Clayton 1994, 171. Ver também Reeves 1990.

${ }^{47}$ James et Morkot 2010, 255.

48 A câmara funerária do túmulo de Ramsés XI apresentava um poço no lugar onde o sarcófago havia de ser depositado. No fundo do poço foram encontradas peças fragmentadas provenientes de equipamentos funerários de diversos faraós: fragmentos de loiça de faiança azul com o nome de Hórus de Tutmés I e de Ramsés II; fragmentos de gesso dourado, alguns espoliados do ataúde de Tutmés III, estilhaços de estatuetas funerárias reais provenientes do KV 34, dois deles com o nome de coroação de Tutmés III, fragmentos de um ataúde feminino real, possivelmente pertencente a Hatchepsut e três estatuetas funerárias de Ramsés IV (Wilkinson 1996, 173).

${ }^{49}$ Pinedjem I apresenta o título de rei no Templo de Khonsu, bem como na inscrição do Ano 8 do seu reinado, e na inscrição do Ano 16 (de Herihor?), sendo então Masaharta sumo pontífice (Goff 1979, 56). 
Com Smendes I (1069-1043), em Tânis, e Pinedjem I (1070-1032), em Tebas, as referências à «Repetição do Nascimento» terminam. Chegara ao fim a Uhem-mesut que durara apenas doze anos (1080-1069) ${ }^{50}$, ao longo dos quais uma transição eficaz para uma nova configuração política foi plenamente assegurada. Não se conhece ainda qualquer vestígio acerca do local de enterramento do faraó Herihor, nem tão-pouco de Ramsés XI, os grandes obreiros desta transformação política, mas é muito possível que ambos tenham sido sepultados no mesmo túmulo coletivo, ainda por localizar.

\section{A RAMificaÇÃo do PODER}

Embora em segundo plano na trama historiográfica da «Repetição do Nascimento», o papel desempenhado por Ramsés XI parece ter sido decisivo numa reforma que iria transformar o exercício do poder ao longo de todo o Terceiro Período Intermediário. Embora silencioso, é o seu vulto que se adivinha decisivo nos bastidores da cena política para a afirmação dos chefes militares líbios no contexto tebano e para a subsequente redefinição do poder político no Egito. Em boa verdade, o clero amoniano foi decepado da sua cúpula - os sumo sacerdotes de Ámon - e foi subordinado ao domínio de chefes militares que, embora egipcianizados, não conseguiam ou não queriam disfarçar a sua origem líbia.

A aliança entre o faraó e os chefes militares de origem líbia coloca grandemente em causa a imagem frequentemente divulgada de Ramsés XI como um monarca fraco. Os dados são longe de serem conclusivos mas é uma forte possibilidade a ter em conta o envolvimento direto do faraó nos acontecimentos que levaram à deposição de Amen-hotep e à subsequente expulsão de Panehesi para a Núbia. Num só golpe, os dois homens fortes do momento foram afastados. Estes factos desencadearam uma forte tensão em Tebas e levariam à implementação da "Repetição dos Nascimento», que mais não foi do que um hábil e eficaz sistema para implantar na mais elevada hierarquia tebana a casta militar «líbia», que manifestou sempre uma fidelidade inquestionável ao faraó.

No início da XXI dinastia, o Egito era constituído por dois estados que aplicavam entre si os princípios do relacionamento diplomático, fomentando estreitos laços familiares. Os sumo sacerdotes de Ámon detinham autoridade sobre todo o Alto Egito desde Uauat (região norte da Núbia) até El-Hiba (a sul do Faium) ${ }^{51}$. A jurisdição prática dos faraós que reinavam em Tânis (Djanet, em egípcio) abrangia o Delta e a região do Faium. A fronteira formal entre os dois estados foi delimitada em El-Hiba, a sul do braço do Nilo que desagua no Faium.

\footnotetext{
${ }^{50}$ Araújo 1999, 130.

${ }^{51}$ Taylor 2000, 331.
} 
Sinal que esta fronteira não era apenas simbólica é a construção de fortalezas nesta área ${ }^{52}$.

Tânis, a nova capital do Delta, era a sede espiritual da nova linhagem real, inteiramente construída com materiais reutilizados da antiga capital ramséssida, Pi-Ramsés. A sacralidade do seu estatuto foi robustecida com a sua eleição como necrópole real. Tebas, no sul, era a sede inquestionável da nova teocracia de Ámon, o qual era o verdadeiro rei do Egito. Neste sistema político, as decisões eram formalizadas através de consulta oracular por ocasião do Festival da Divina Audiência, sediada em Karnak ${ }^{53}$. A Viagem de Uenamon documenta cruamente até que ponto o novo sistema implementado em Tebas com êxito se desfasara da realidade política internacional. Quando o poderoso deus tebano encomendou uma nova barca sagrada, Herihor confiou a Uenamon a importante missão de adquirir madeira de cedro em Biblos, mas aparentemente não achou relevante incluir na bagagem do fiel emissário a prata necessária ao pagamento da preciosa madeira. Diante do Príncipe de Biblos, Uenamon não pôde senão avançar como retribuição a simples mas generosa promessa de muitos e felizes anos de vida concedidos pelo poderoso Ámon ao Senhor de Biblos. Este, no entanto, viu-se na obrigação de lembrar a Uenamon como os seus antepassados haviam negociado: trocando a madeira pela prata. A situação acabou por ser desbloqueada por Smendes que assegurou o pagamento exigido pela madeira ${ }^{54}$. A situação ilustra soberbamente o desfasamento atingido pelo sistema político tebano, o qual se baseava num isolamento cultural e civilizacional sem precedentes.

Apesar de entidades políticas distintas, os dois reinos eram no entanto lideradas manifestamente pela mesma família ${ }^{55}$.

Com a bipolarização do Egito em dois reinos, a XXI dinastia é, em grande medida, um prelúdio para a organização política do chamado "período líbio» (XXII-XIV dinastias), o qual, na prática, é iniciado com Herihor. O monopólio do poder que sempre havia caracterizado o Egito, deu lugar a um sistema de alianças, no qual os vários pequenos estados se protegiam uns dos outros por forças militares próprias ${ }^{56}$. O monopólio dos impostos foi substituído por tributos. A «feudalização» da burocracia egípcia foi uma consequência da ascensão dos líbios às posições de topo da sociedade egípcia ${ }^{57}$. O Egito não escapou, portanto, aos efeitos que afetaram a queda dos impérios do Bronze ${ }^{58}$.

\footnotetext{
52 Taylor 2000, 333.

${ }^{53}$ Taylor 2000, 332.

${ }^{54}$ Assmann 2002, 294.

${ }^{55}$ Goff $1979,70$.

56 Taylor 2000, 338-46.

${ }^{57}$ Assmann 2002, 296.

${ }^{58}$ Assmann 2002, 296.
} 
Este processo, contudo, não foi visto como uma sujeição a um poder estrangeiro, algo que só será verdadeiramente sentido sob a dominação assíria e persa. Nem tão pouco a desintegração política foi sentida como um tempo de caos, como até aí sempre acontecera e a fragmentação do país não originou qualquer elaboração sobre a inversão da ordem cósmica.

A «Repetição do Nascimento» fundou uma nova estrutura política muito diferente da que havia caracterizado os impérios do Bronze. É neste curto período temporal e aparentemente sem as convulsões sociais e militares que caracterizaram esta transição noutros quadrantes, que se reorganizou o exercício do poder e se reformou o quadro teológico que o legitimava, garantindo assim a reactualização do complexo sistema faraónico no contexto das civilizações da Idade do Ferro.

A «Repetição do Nascimento» consistiu, portanto, num período de transição em que, com uma surpreendente agilidade e rapidez, se procedeu à reforma das milenares estruturas políticas do Egito e se criaram as fundações que haveriam de garantir a manutenção do Egito no mapa político e civilizacional do Mediterrâneo por mais de um milénio. 


\section{Bibliografia}

Assmann, J. 2002. The Mind of Egypt: History and meaning in the time of the Pharaohs. Cambridge, MA / London: Harvard University Press.

Araújo, L. 1999. O clero do deus Ámon no Antigo Egipto. Lisboa: Edições Cosmos.

Barguet, P. 1962. Le Temple d'Ámon-Rê à Karnak: Essai d'Exégèse. Le Caire: Institut Français d'Archaeologie Orientale.

Bickerstaffe, D. 2009. Refugees for Eternity: The Royal Mummies of Thebes. Vol. 4. London: Canopus Press.

Bierbrier, M. 1975. The late New Kingdom in Egypt (c. 1300-664 BC): A genealogical and chronological investigation. Warminster: Aris \& Philips.

Černý, J. 1965. "Egypt: from the dead of Ramesses III to the end of the 21st Dynasty." In The Cambridge Ancient History II (The Middle East and the Aegean Region c. 1300-1000 BC), ed. I. E. S. Edwards, C. J. Gadd, N. G. L. Hammond e E. Sollberger, 606-57. Cambridge: Cambridge University Press.

. 1946. "Studies in the chronology of the twenty-first dynasty." The Journal of Egyptian Archaeology 32:24-30.

— 1927. "A note on the 'Repetition of births." The Journal of Egyptian Archaeology 15:194-98.

Cooney, K. 2011. "Changing burial practices at the end of the New Kingdom: Defensive adaptations in tomb commissions, coffin commissions, coffin decoration and mummification." Journal of the American Research Center in Egypt 47:3-44.

Clayton, P. 1994. Chronicle of the Pharaohs: The reign-by-reign record of the rulers and Dynasties of Ancient Egypt. London: Thames \& Hudson.

Dodson, A. 2012. Afterglow of Empire: Egypt from the fall of the New Kingdom to the Saite Renaissance. Cairo / New York: The American University Press.

Elias, J. 1993. "Coffin inscription in Egypt after the New Kingdom: A Study of Text Production and Use in Elite Mortuary Preparation.” Dissertação de Doutoramento apresentada ao Departamento de Antropologia da Universidade de Chicago.

Epigraphic Survey. 1979-1981. Scenes and Inscriptions in the court and the first Hypostyle hall. The Temple of Khonsu. 2 vols. Chicago: Oriental Institute Publications.

Gardiner, A. 1961. Egypt of the Pharaohs. An Introduction. London / Oxford / New York: Oxford University Press.

Goedicke, H. 1975. The Report of Wenamun. Baltimore: John Hopkins Near Eastern Studies. 
Goelet, O. 1996. “A new "robbery" papyrus: Rochester Mag 51.346.1." The Journal of Egyptian Archaeology 82:107-27.

Goff, B. 1979. Symbols of Ancient Egypt in the Late Period. Twenty-first Dynasty. The Hague / Paris / New York: Mouton Publishers.

James, P. e R. Morkot. 2010. "Herihor's kingship and the High Priest of Amun Piankh.” Journal of Egyptian History 3 (2):231-60.

Kitchen, K. 1986. The Third Intermediate Period in Egypt. Warminster: Aris \& Phillips.

— 1982-1983. "Further thoughts on Egyptian chronology in the Third Intermediate Period." Revue d'Egyptologie 34:59-69.

_. 1965. "On the chronology and history of the New Kingdom." Chronique d'Egypte 40:310-22.

Lefebvre, G. 1929. Histoire des Grands Prêtres d' Ámon de Karnak jusqu'a la XXI dynastie. Paris: Paul Geuthner.

Nims, C. 1948. "An Oracle dated in the 'Repetition of Births'." Journal of Near Eastern Studies 7:157-62.

Niwinski, A. 1979. "Problems in the Cronology and genealogy of the XXI dynasty: New proposals for their interpretation." The Journal of the American Research Center in Egypt 16:49-68.

Peet, E. 1930. The Great Tomb Robberies of the Twentieth Egyptian Dynasty: being a critical study, with translations and commentaries, of the papyri in which these are recorded. Oxford: Clarendon Press.

— 1928. "The chronological problems of the Twentieth Dynasty." The Journal of Egyptian Archaeology 14:52-72.

Polz, D. 2001. “Thebes”. In Oxford Encyclopaedia of Ancient Egypt. Vol. 3, ed. D. Redford, 384-87. Cairo: The American University in Cairo Press.

Reeves, N. 1990. The Valley of the Kings: The decline of a royal necropolis. London / New York: Kegan Paul International.

Taylor, J. 2000. “The Third Intermediate Period." In The Oxford History of Ancient Egpyt, ed. I. Shaw, 330-68. Oxford: Oxford University Press.

1998. "Nodjmet, Payankh and Herihor: The end of the New Kingdom reconsidered." In Proceedings of the Seventh International Congress of Egyptologists, ed. C. Eyre, 1144-55. Leuvein: Peeters.

Trigger, B, B. Kemp, D. O'Connor e A. Lloyd. 1983. Ancient Egypt: A social history. Cambridge: Cambridge University Press.

Wainwright, G. A. 1962. “The Meshwesh.” The Journal of Egyptian Archaeology 48:89-99. 


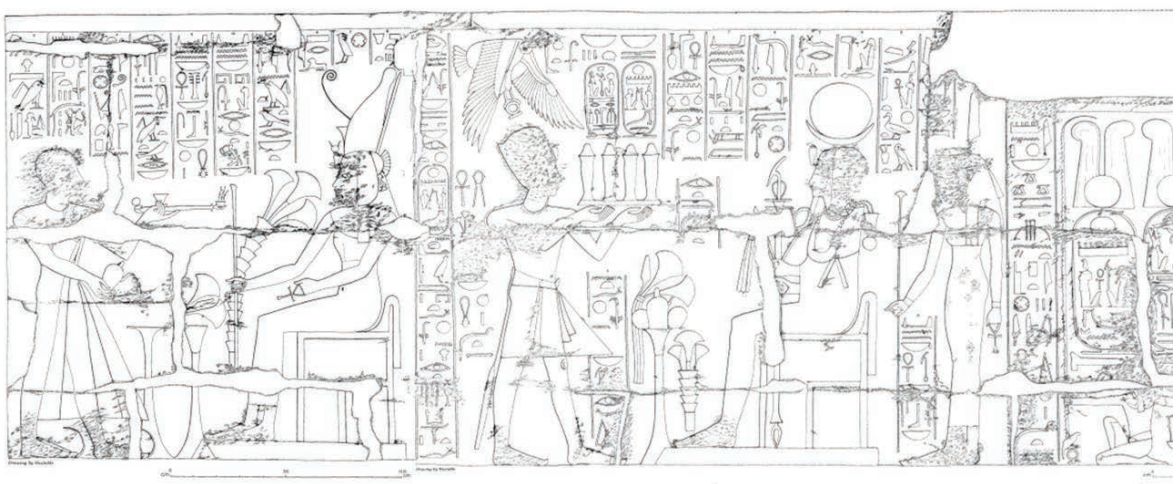

Fig. 1 - Herihor, na qualidade de sumo pontífice, oficia diante de Mut (esquerda) e Ramsés XI diante de Khonsu (direita). Sala hipostila do Templo de Khonsu, em Karnak.

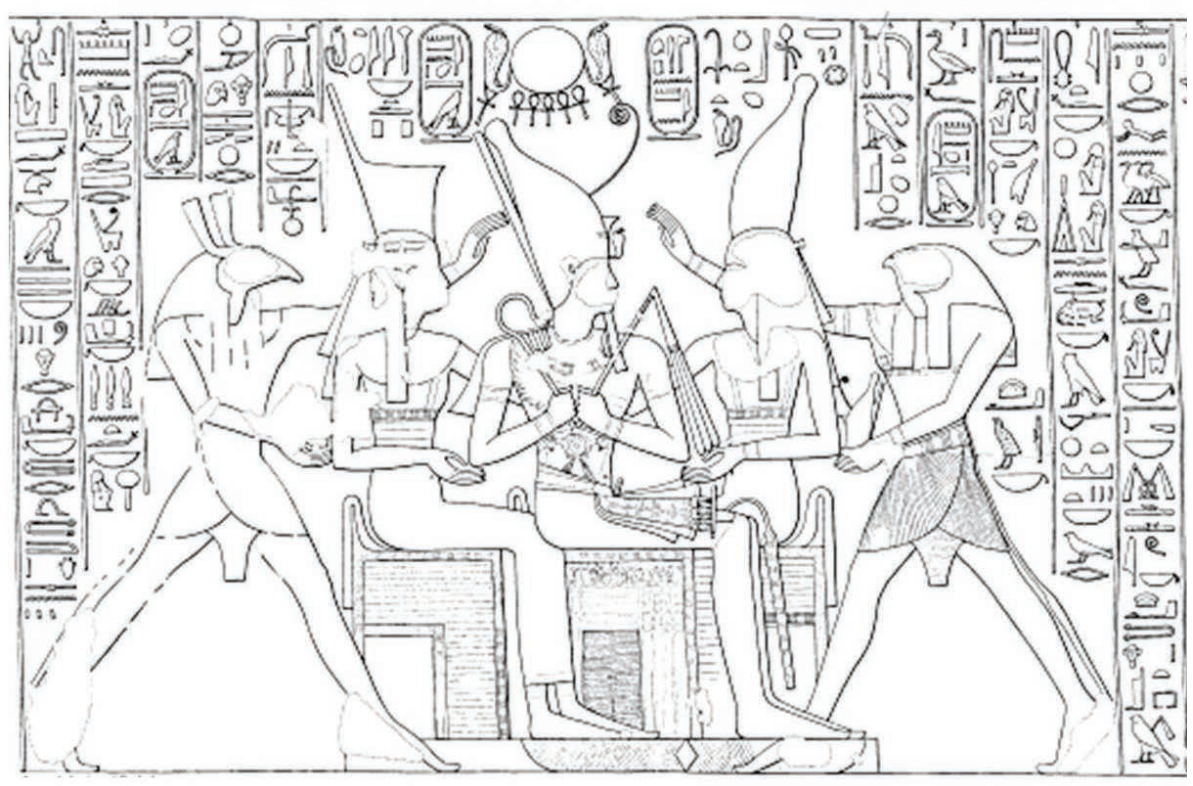

Fig. 2 - Entronização do faraó Herihor. Pátio do Templo de Khonsu, em Karnak. 

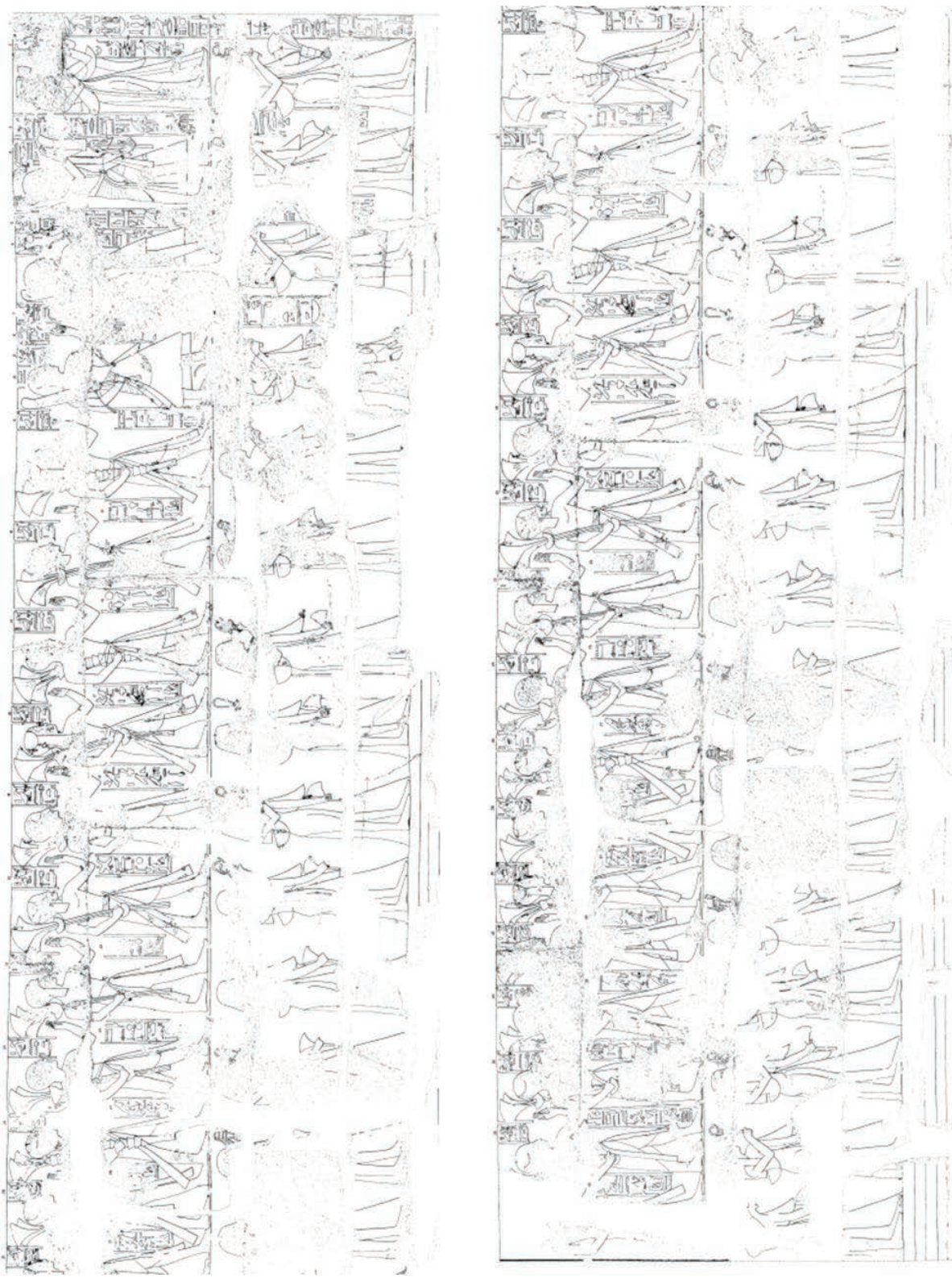

Fig. 3 - Cortejo liderado por Nedjemet (em cima à direita) dos filhos e filhas de Herihor. Pátio do Templo de Khonsu, em Karnak. 
